\title{
The correct diagnosis and therapeutic management of tear dysfunction: recommendations of the P.I.C.A.S.S.O. board
}

\author{
Maurizio Rolando • Emilia Cantera • Rita Mencucci • Pierangela Rubino • \\ Pasquale Aragona $(1)$
}

Received: 14 January 2017/ Accepted: 4 April 2017/Published online: 10 April 2017

(C) The Author(s) 2017. This article is an open access publication

\begin{abstract}
Purpose To describe a standard approach to manage tear dysfunction (TD), in order to obtain a clinically favourable outcome. TD is a highly prevalent, yet largely underdiagnosed, condition that affects from 5 to $30 \%$ of the population above 50 years old. Left untreated, TD is associated with eye discomfort and ocular surface disease, substantially affecting quality of life. Although the prevalence of this problem is increasing significantly, a standard approach to its prevention and treatment is not available yet.
\end{abstract}

Partners Italiani per la Correzione delle Alterazioni del Sistema della Superficie Oculare/Italian Partners for the Correction of Ocular Surface Alterations.

M. Rolando

IsPre Oftalmica, Ocular Surface Center, Genoa, Italy

E. Cantera

Israelitic Hospital, Rome, Italy

R. Mencucci

Eye Clinic, University of Firenze, Florence, Italy

P. Rubino

Eye Clinic, Azienda Ospedaliero-Universitaria di Parma,

Parma, Italy

P. Aragona $(\square)$

Eye Clinic, Department of Biomedical Sciences,

University of Messina, Messina, Italy

e-mail: paragona@unime.it
Methods In September 2015, a team of Ocular Surface Italian Experts convened for a roundtable to discuss on the latest knowledge about diagnosis and treatments for TD and the real issues in the management of these patients. The discussion centred on the appropriate definition of $\mathrm{TD}$, proposing a new classification of risk factors and how to identify them, how to make a correct diagnosis choosing the rational therapy (questionnaires, symptoms' time relation, seasonality, low tech diagnostic manoeuvres, specific tests for the detection of tear film disturbances leading to recognition of the level of disease and of the ocular system elements involved), which artificial tear matches the ideal profile for a rational therapy and which questions should be done to the patient. Results A multi-item flowchart for tear film dysfunction, with point-by-point explanatory guide, to better identify and manage the patient with this disorder is provided.

Conclusions The growing prevalence of TD demands increased attention. An appropriate prevention and a treatment pattern for the patient, combined with greater patient-practitioner interaction, and patient education is offered.

Keywords Tear dysfunction - Ocular surface . Diagnosis - Treatment

\section{The current understanding of tear dysfunction}

Tear dysfunction (TD) is a disease frequently encountered in the clinical practice, characterised by an 
impairment of the ocular surface. The prevalence ranges between 5 and $33 \%$ of the world's adult population [1, 2]. It is a chronic and progressive condition whose symptoms vary greatly from virtually none to invalidating.

The continuously growing number of patients who are referred from general ophthalmology outpatient clinics to specialist centres confirms this epidemiological finding.

It is a multifactorial disease that affects one or more elements of the ocular surface functional unit, which includes tear film, cornea, limbus, conjunctiva, lid margin muco-epidermal junction, and lacrimal gland tubuloacinar epithelia, as well as lacrimal drainage system, and eyelids. The epithelia have an intense and continuous glycoprotein secretory activity, which maintains excellent relations with the lacrimal fluid. Moreover, they mutually affect each other in a simultaneous response for the maximal functional efficacy of the system [2-5].

The system also includes the eyelids and the nasolacrimal duct and recognises the supplementary functions of the immune, vascular, nervous and endocrine systems, which are useful for the refractive and protective properties of the tear film.

A sufficient amount of tears, a stable and even composition and architecture of the tear film, proper eyelid closure with normal blinking and suitable tear film turnover are the prerequisites for maintaining the homoeostasis of the ocular surface. Whatever the cause, the absence of these conditions is behind the Tear Dysfunction Syndrome (or Dry Eye Disease) [5].

If the ocular surface cannot adapt and quickly correct this "malfunction", it enters a vicious circle, which leads to chronic damage and, subsequently, to the disease (Fig. 1).

As all patients present with chronic ocular surface disorders, patients with TD always have the typical signs of system failure including tear instability, epithelial suffering, and inflammation (Fig. 2).

Tear instability, or altered tear composition, drives the pathogenic process and is always associated with subclinical or clinically evident inflammation. Tear film instability can be caused by excessive evaporation, which results in an increased concentration of electrolytes. Hypertonicity in the epithelial environment involves the onset of inflammation and tissue damage [5-7].

Other causes of tear instability are primary tear hyposecretion (due to direct malfunction of the main glands) and secondary tear hyposecretion (e.g. prolonged inflammation resulting in reduced efficiency of the corneal nervous system, or anterior segment surgery). In these cases, inflammation is a consequence of the reduced tear clearance, which results in a reduced supply of epithelial growth and regulation factors and an increased in situ permanence of toxic factors that come from epithelial metabolism or the surrounding environment. Over time, the inflammation involves also the corneal nerve fibres and the eyelid glands, thereby triggering and maintaining the multiple pathogenic vicious circles, which characterise this disease. It is important to stress that the underlying inflammation is a key element, regardless of the factors that have caused it [8-11].

Tear Dysfunction Syndrome (or Dry Eye Disease) is a complex disease, which tends to sustain itself through the creation of vicious circles. As with all ocular surface disorders, three pathogenic factors are always present with different levels of expression according to the clinical presentations and level of the disease. These factors are: (1) tear instability, (2) epithelial malfunction and/or suffering and (3) more or less clinically evident inflammation $[12,13]$.

In summary, we can state that TD is part of the discomfort of the eye surface. The common name "dry eye" is linked to the concept of lack of tears. However, it is important to stress that the problem is that tears do not function because the ocular surface is not functioning.

\section{Medical history and local and general risk factors: identification and classification}

Patients with TD often report eye conditions such as photophobia, foreign body sensation (or rather, in the words of the patients, "sand in eye feeling"), burning, itchiness, dryness, eye fatigue and pain. Patients can also develop redness, contact lens intolerance and, in some cases, mucus secretion. Most patients report a series of symptoms and not just one. It is interesting to stress that lacrimation is also a reported symptom, although it is mainly present in the early stages of the disease. Excess lacrimation is to be considered a paradoxical lacrimal reflex, since basal tear secretion is reduced in the event of dry eye [2].

The above-described symptoms are universally accepted by the scientific community. On the other 
Fig. 1 Dysfunctional tear film pathogenesis and maintenance. $M G D$ meibomian gland dysfunction, $M M P$ matrix metalloproteinase Adapted from DEWS 2007

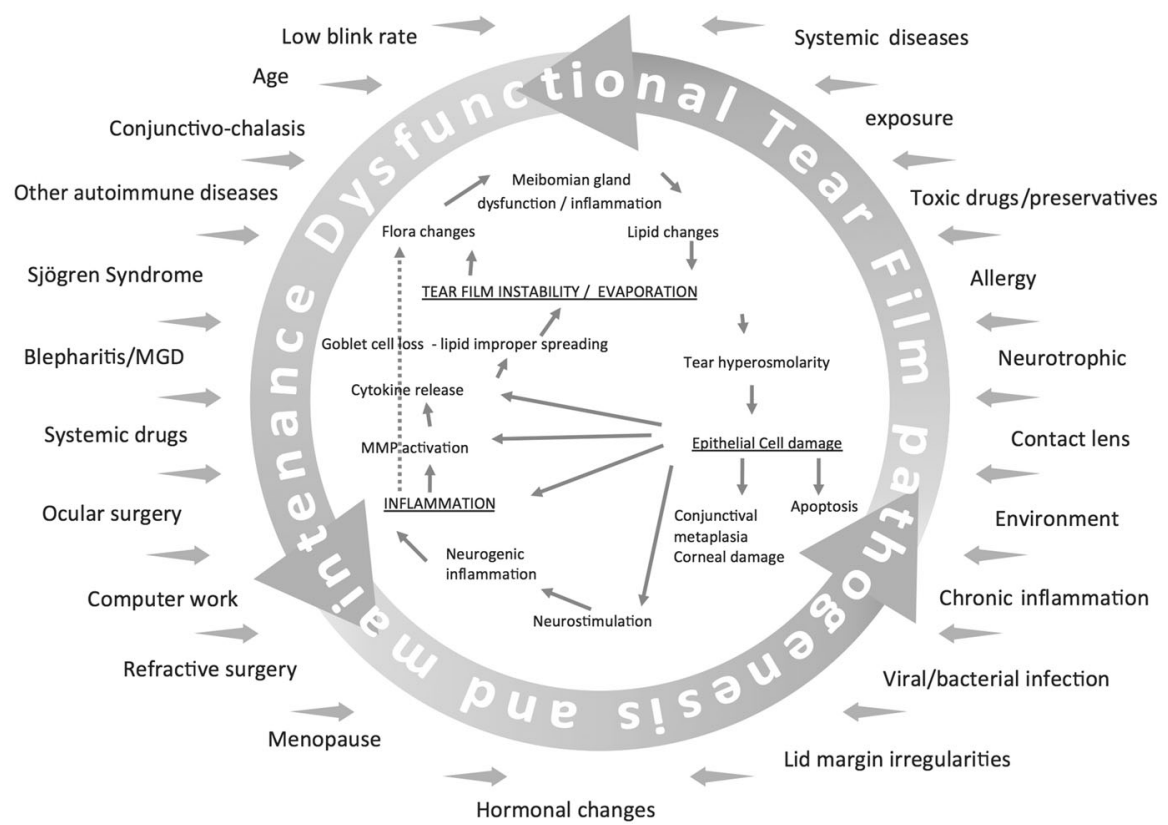

always start with the identification of general and local risk factors, which can increase or predispose to a higher risk of ocular surface discomfort.

Risk factors can be general or local (Tables 1,2).

A number of considerations about risk factors for Tear Dysfunction Syndrome (or Dry Eye Disease) should be raised:

Why advanced age?

Tear production decreases with age due to the progressive involution of the lacrimal glands and nerve activities that regulate them. The continuous and consistent decrease in basal tear secretion and the resulting eye irritation often lead to an excessive production of reflex tears [2].

Why are women more exposed?

In women aged between 40 and 60 years, the secreting portion of lacrimal glands undergoes progressive atrophy due to the new hormonal balance induced by menopause. Moreover, after menopause, androgen/ oestrogen imbalance leads to the loss of control over inflammation typical of the androgenic component. Oestrogenic activity, which facilitates inflammation, can occur more easily $[2,16]$. 
Table 1 The three main pathogenic factors of the lacrimal dysfunction

\begin{tabular}{|c|c|c|c|c|c|c|}
\hline \multicolumn{3}{|c|}{ Tear film instability } & \multicolumn{2}{|c|}{ Epithelial suffering } & \multicolumn{2}{|l|}{ Inflammation } \\
\hline $\begin{array}{l}\text { Reduced } \\
\text { tear } \\
\text { volume }\end{array}$ & Poor clearance & $\begin{array}{l}\text { Changes in } \\
\text { rheology } \\
\text { and } \\
\text { viscoelastic } \\
\text { activity }\end{array}$ & $\begin{array}{l}\text { Changes in the } \\
\text { secretory } \\
\text { activity, } \\
\text { altered mucus } \\
\text { glycoproteins }\end{array}$ & $\begin{array}{l}\text { Reduced cell } \\
\text { mobility and } \\
\text { adhesion, } \\
\text { apoptosis }\end{array}$ & $\begin{array}{l}\text { Epithelial } \\
\text { damage }\end{array}$ & $\begin{array}{l}\text { Reduced tear secretion, } \\
\text { reduced clearance }\end{array}$ \\
\hline $\begin{array}{l}\text { Direct } \\
\text { epithelial } \\
\text { trauma }\end{array}$ & $\begin{array}{l}\text { Hyperosmolarity. } \\
\text { Increased } \\
\text { presence of } \\
\text { inflammatory } \\
\text { cytokines }\end{array}$ & $\begin{array}{l}\text { Discomfort } \\
\text { when } \\
\text { blinking. } \\
\text { Foreign body } \\
\text { sensation }\end{array}$ & $\begin{array}{l}\text { Tear } \\
\text { instability, } \\
\text { vision } \\
\text { disturbances, } \\
\text { blinking } \\
\text { disorders }\end{array}$ & $\begin{array}{l}\text { Punctate keratitis, } \\
\text { pain, } \\
\text { photophobia, } \\
\text { vision } \\
\text { disturbances, } \\
\text { inflammatory } \\
\text { stimulus }\end{array}$ & $\begin{array}{l}\text { Keratitis and } \\
\text { conjunctivitis, } \\
\text { pain, alteration } \\
\text { and loss of } \\
\text { muciparous } \\
\text { cells }\end{array}$ & $\begin{array}{l}\text { Maintenance of } \\
\text { inflammation, } \\
\text { recruitment of } \\
\text { antigen-presenting } \\
\text { cells, shift to adaptive } \\
\text { immune reactions }\end{array}$ \\
\hline
\end{tabular}

Table 2 Risk factors classification

\begin{tabular}{ll}
\hline General & Local \\
\hline Advanced age & Surgery (refractive, cataract) \\
Gender (higher incidence in women) & Chronic therapies (glaucoma, vasoconstrictors) \\
Long-term and specific pharmaceutical therapies & Use of drugs with preservatives \\
Hormonal disorders & Blepharitis \\
Haematopoietic stem cell transplantation & Recent infections \\
Diabetes & Use of eye drops \\
Chemotherapy & Eye allergies \\
Environment & Use of contact lenses \\
Professional activity & \\
Autoimmune diseases & \\
Lifestyle (smoking, drinking, balanced diet) & \\
Dermatitis & \\
Menopause & \\
Allergies & \\
Pregnancy & \\
Hypovitaminosis A & \\
Hepatitis C & \\
\hline
\end{tabular}

Why the environment?

High altitude with increased UV exposure, sunny, dry, or windy weather conditions, environments with operating heating or air conditioning systems, increase tear evaporation and oxidative stress, thereby reducing eye lubrication [2].
What are the risks of those who wear contact lenses?

Their use can increase tear evaporation significantly, causing irritation and infections. Corneal lens disinfecting and lubricating solutions can alter the lacrimal gland and tear production. Moreover, if the eye is not 
lubricated enough, the lens tends to adhere to the cornea, causing damage, which can be serious (abrasion, keratitis) [2, 17].

Are there drugs that increase the risks of developing tear dysfunction?

Some drugs (hormones, immunosuppressants, decongestants, antihistamines, diuretics, antidepressants, beta blockers, heart disease- and ulcer-treating drugs) can inhibit the production of efficient tears [2].

The impact of drugs and polypharmacy

With age, the number of drugs administered systemically increases. As we have seen, many of these drugs can interfere with tear production (Tables 3,4).

A fundamental step in taking a medical history is to try to know which drugs have been administered systemically, because every agent that can interfere with one or more tear film components (lipids, water, mucins) can disrupt the stability of the tear film and cause or worsen the typical dry eye symptoms. Physician's Desk Reference reports that $56 \%$ of the top 100 drugs sold in the USA in 2009 can cause eye dryness and $22 \%$ has a proven negative effect on tear secretion [18].

Table 3 Classes of systemic medications that can induce dry eye and dry mouth

\begin{tabular}{ll}
\hline Class of drugs & \\
\hline Anaesthesia adjuvants & Antipyretics \\
Analgesics & Antirheumatics \\
Antiandrogens & Spasmolytics \\
Antiarrhythmics & Antiviral drugs \\
Anticholinergic drugs & Anxiolytics \\
Antidepressants & Bronchodilators \\
Antiemetics & Chelating agents \\
Antihistamines & Decongestants \\
Antihypertensives & Diuretics \\
Antileprotics & Neurotoxins \\
Antimalarials & Opioids \\
Antimuscarinics & Psychedelic agents \\
Antineoplastics & Retinoids \\
Antiparkinson drugs & Sedatives-hypnotics \\
Antipsychotics & \\
\hline
\end{tabular}

With age, there is a significant reduction in tear secretion associated with an increase in the number of systemic medications. After a while of taking drugs for other intercurrent diseases, these patients will start manifesting the typical signs of dry eye, while patients who already suffered from eye dryness will see their symptoms worsen [2, 19-23].

Most of these preparations lead to eye dryness through an anticholinergic mechanism. In fact, they compete with acetylcholine in the postsynaptic muscarinic receptor in the peripheral and/or central nervous system, thereby blocking the acetylcholineinduced stimulation of lacrimal gland and conjunctival muciparous goblet cell secretion.

\section{Antidepressants and anxiolytics}

Antidepressants are among the major causes of TD. In particular, tricyclic and heterocyclic antidepressants (amitriptyline, imipramine, nortriptyline, etc.) seem to be more harmful than selective serotonin reuptake inhibitors (fluoxetine, sertraline, paroxetine). It is worth reminding that these preparations are frequently used to treat anxiety and chronic pain. Therefore, they are often prescribed to patients with persistent forms of dryness, who present with anxiety and depression due to this condition.

Benzodiazepines (e.g. diazepam, alprazolam) used as anxiolytics also have anticholinergic effects, as do $\mathrm{H}_{2}$ receptor antagonists (e.g. cimetidine, ranitidine, famotidine) used as gastroprotectants and gastric motility regulators.

\section{Antiparkinson drugs}

Antiparkinson drugs, such as levodopa and pramipexole, have an anticholinergic effect, which adds up to the rare and incomplete blinking (typical in these patients) in threatening ocular surface homoeostasis and inducing TD.

\section{Antihistamines}

$\mathrm{H}_{1}$-antihistamines used for treating allergic rhinitis have an anticholinergic activity. These are often associated with decongestant vasoconstrictors, which reduce lacrimal gland blood flow. The effect of decongestants and antihistamines in the form of nasal sprays must not be underestimated, because abundant 
Table 4 Systemic drugs that may induce or worsen dry eye http://www. eyedrugregistry.com/

\begin{tabular}{|c|c|}
\hline Class & Examples \\
\hline Antihypertensives (beta-agonists) & Acebutolol \\
\hline Antihypertensives (alpha agonists) & Atenolol \\
\hline \multirow[t]{9}{*}{ Antiarrhythmics (beta blockers) } & Carvedilol \\
\hline & Labetalol \\
\hline & Metoprolol \\
\hline & Corgard \\
\hline & Pindolol \\
\hline & Clonidine \\
\hline & Prazosin \\
\hline & Oxprenolol \\
\hline & Propranolol \\
\hline \multirow[t]{15}{*}{ Antipsychotics } & Chlorpromazine \\
\hline & Fluphenazine \\
\hline & Lithium carbonate \\
\hline & Perphenazine \\
\hline & Prochlorperazine \\
\hline & Promethazine \\
\hline & Quetiapine \\
\hline & Thiethylperazine \\
\hline & Thioridazine \\
\hline & Brompheniramine \\
\hline & Carbinoxamine \\
\hline & Chlorphenamine (chlorpheniramine) \\
\hline & Clemastine \\
\hline & Cyproheptadine \\
\hline & Dexchlorpheniramine \\
\hline Bronchodilators & Diphenhydramine \\
\hline Antispasmodics/antimuscarinics & Doxylamine \\
\hline \multirow[t]{7}{*}{ Antiarrhythmics } & Ipratropium bromide \\
\hline & Atropine \\
\hline & Homatropine \\
\hline & Tolterodine \\
\hline & Hyoscine (scopolamine) \\
\hline & Hyoscine methobromide (methscopolamine) \\
\hline & Disopyramide \\
\hline \multirow[t]{7}{*}{ Antineoplastics } & Busulfan \\
\hline & Cyclophosphamide \\
\hline & Interferon (alpha, beta, gamma, or PEG) \\
\hline & Vinblastine \\
\hline & Cetuximab \\
\hline & Erlotinib \\
\hline & Gefitinib \\
\hline \multirow[t]{4}{*}{ Antihistamines } & Cetirizine \\
\hline & Desloratadine \\
\hline & Fexofenadine \\
\hline & Loratadine \\
\hline
\end{tabular}


Table 4 continued

Class

Antidepressants

Examples

Olopatadine

Tripelennamine

Citalopram

Fluoxetine

Fluvoxamine

Paroxetine

Sertraline

Antileprotics

Clofazimine

Antirheumatics/analgesics

Aspirin

Ibuprofen

Sedatives-hypnotics

Primidone

Drugs secreted in tears

Aspirin

Chloroquine

Clofazimine

Docetaxel

Ethanol

Hydroxychloroquine

Ibuprofen

Isotretinoin

Antiandrogens

Tamsulosin

Terazosin

Doxazosin

Neurotoxins

Alfuzosin

Antimalarial agents

Botulinum toxin A or B

Chloroquine

Hydroxychloroquine

Retinoids

Isotretinoin

Antiviral drugs

Thiazides

Aciclovir

Bendroflumethiazide

Chlorothiazide

Chlorthalidone

Hydrochlorothiazide

Hydroflumethiazide

Indapamide

Methyclothiazide

Metolazone

Polythiazide

Trichlormethiazide

Cannabinoids

Dronabinol

Hashish

Cannabis

Chelating agents

Methoxsalen

Strong analgesics

Morphine

Opium/opioids

Antipsychotic agents 
nasal blood supply causes high levels of drug absorption.

\section{Antihypertensives}

Negative effects on tear stability have been reported with the use of antihypertensives, such as beta blockers, which can reduce the levels of lysozyme and immunoglobulin A, as well as tear fluid production. In addition, they can produce a certain level of corneal anaesthesia, which further reduces tear production stimulation.

Even diuretics, such as hydrochlorothiazide and furosemide and triamterene, commonly used to treat hypertension, myocardial infarction and cardiac decompensation, induce eye dryness [24, 25].

\section{Hormones}

The use of oestrogens or oestrogen and progestin combinations (often prescribed as contraceptives or in postmenopausal hormone replacement therapies) is often associated with dry eye symptoms. The exact cause-effect correlation is still unknown; however, it is thought that there is an influence on mucus secretion and a possible link with the reduced production of tear fluid. Experimental data have shown that mucus secretion is influenced by the hormonal status even in physiological conditions [26].

Debra A. Schaumberg's group has reported a $69 \%$ increase in dry eye symptoms in women who were taking oestrogens compared to the control group [16]. On the other hand, women who were taking progesterone alone or in combination after menopause showed a $29 \%$ increase in dry eye symptoms compared to the control group. These data highlight the significant risk of developing dry eye in oestrogentreated patients.

Drugs used for treating overactive bladder syndrome (oxybutynin, tolterodine, fesoterodine) and antispasmodics for treating reflux syndromes and stomach disorders also have anticholinergic effects.

Furthermore, it is important to consider the effect of isotretinoin (via oral route) used in acne treatment, as it could induce meibomian gland atrophy with a negative impact on tear film stability [27, 28].

\section{Polypharmacy}

Polypharmacy is commonly defined as the use of 5 or more prescription drugs. This is a typical and growing problem in the older population. One study has shown that $12 \%$ of subjects over 60 years of age used 2 prescription drugs, $27.3 \%, 3$ or 4 , and $36.7 \%, 5$ or more. In addition, an average of at least 2 OTC products (vitamins, aspirins, decongestants, etc.) and herbal preparation are used on a daily basis [29-32].

Although some drugs taken alone are not responsible for ocular surface damage, this may be the case when administered in combination with others, thus creating a negative synergism. Therefore, this aspect should be considered during the diagnosis. For example, it can be useful to ask the patient "are you undergoing any treatment (e.g. for hypertension, diabetes, etc.)?", "how many and what type of drugs or supplements are you taking?", "do you ever get dry mouth?", "do you feel eye discomfort?".

Polypharmacy can be a problem, because many medications interact with each other in not easily predictable ways. Sometimes, drug interaction can exceed the side effect threshold, which cannot be noticed when the drug is used alone.

Moreover, there is enough evidence that polypharmacy is a cause of dry mouth. The prevalence of dry mouth in the population that used more than 4 systemic drugs was up to $82 \%$.

The role played by medications that can induce or worsen TD has not been analysed in-depth in targeted studies but only in incidental findings. However, despite being incomplete, these data provide enough information for drawing a few considerations:

- The role of systemic medications and systemic absorption of topical medications in inducing eye dryness is greatly underestimated;

- It is important to know whether the various drugs can have additive or even synergistic side effects;

- The role of oral polypharmacy in inducing or worsening dry eye must be analysed in-depth and taken into clinical consideration, including not only systemic prescription drugs but also topical, OTC drugs, and herbal preparations, when taking the medical history;

- The drug's administration time may also play a role in causing symptoms of dryness. 


\section{Patient counselling}

Tear dysfunction remains an underdiagnosed and underestimated problem, despite recent publications [2].

Patients are sometimes difficult to outline because they often use a different language from doctors. On the other hand, doctors sometimes make questions that do not always help to achieve the correct diagnosis of the patient. Not to mention the little time available during an examination for questioning patients about their anamnesis, which may end up with the doctor minimising patient's problem.

It is not uncommon for patients to be mistakenly diagnosed with TD when in fact they are suffering from other disorders. It may also happen that cases of dry eye are misdiagnosed. In other cases, despite the correct diagnosis, the patient's satisfaction and compliance with the therapy prescribed is far than satisfactory. The causes of such problems in the management of TD are often related to a miscommunication between doctors and patients.

Many times, TD diagnosis is based on symptoms (foreign body sensation, burning, lacrimation, desire to keep the eyes closed, dryness, redness, itchiness, intermittent blurry vision, asthenopia). Unfortunately, these symptoms are not exclusive to this disease and may vary greatly from one patient to another. Moreover, there is no correlation between the symptoms reported by the patient and the doctor's findings. For example, according to a questionnaire distributed across Europe, 22-23\% of patients complained about "itchy eyes" and were mistakenly treated with an antiallergy medication [33-35].

The patient interview (medical history) is extremely important. It is essential to give patients enough time to report all symptoms and explain their discomfort. The symptoms reported by the patients help the doctor develop a differential diagnosis. In general, patients who feel better keeping their eyes closed are those with real dry eye.

Once the patient has reported all his/her symptoms, the doctor starts asking specific questions to confirm the suspected disorder and exclude other causes that are frequently mistaken for dry eye. For example, it is useful to ask a patient which environmental conditions improve or worsen the symptoms, and investigate on the presence of other eye disorders (allergic conjunctivitis, lacrimal duct disorders, Thygeson disease, etc.), systemic diseases (diabetes, rosacea, rheumatoid arthritis, thyroid problems, autoimmune diseases), ongoing therapies (antidepressants, gastroprotectants, hormone replacement therapy), hormonal state (peri-, postmenopause), family history (autoimmune diseases, thyroid disorders, diabetes, etc.).

Upon establishing the diagnosis of $\mathrm{TD}$, it is essential to explain to the patient very clearly what it is going on (many patients, for example, are very worried because they associate that "heaviness" with a rise in blood pressure). In particular, the patient must know that this is a chronic disease that cannot be cured, and even the therapy will be chronic and adjusted over time according to the patient's response. It is also important to tell the patient that a correct therapeutic management will allow them to return to a good quality of life, even if the therapy will not provide immediate results.

The patient must be aware that the result will greatly depend on compliance and consistency with the therapy. However, the patient's compliance will depend on how much they understand the information provided by the doctor.

There is a risk of patients to end up in a three-stage vicious circle, during the first stage of which they are hopeful and think that the prescribed eye drops will solve their discomfort. After a certain period, if the treatment is not effective, they may enter the anxiety stage and think "this is getting worse... it's going to ruin my vision... the eye doctor has underestimated my problem... the eye doctor got the diagnosis wrong". At this point, there could be a third stage, in which patients start to look for information on Internet, talk with family and friends, and return to the ophthalmologist with all sorts of questions, worrying that they have all sorts of diseases. Often, the TD diagnosis is not convincing.

All this may justify a paradox. Patients feel more satisfied when they receive a definitive diagnosis, whatever it is. Anxious people, who do not receive a definitive diagnosis, are less likely to comply with the therapy [36]. There is a close association between depression, stress and TD in patients who have been clinically diagnosed with it or those presenting with its symptoms [37].

It is important not to underestimate the disease. For example, when patients say they have a foreign body sensation or a 24-h burning sensation, the ophthalmologist may not fully understand the problem and 
end up minimising it and considering it just a simple discomfort. Instead, it is important for the ophthalmologist to understand the patient's problem and become their greatest ally to ensure an effective therapeutic strategy. It is safe to say that the level of satisfaction of both the patient and the doctor depends on two elements: the ophthalmologist must never minimise the problem and must make the patient aware that TD is a chronic disease.

It is essential to explain to the patient that their symptoms, including lacrimation, depend on a chronic inflammation that can get worse if not treated properly. In addition to the medical therapy, the doctor must provide practical tips: dry environments worsen the symptoms (heating or air conditioning); avoid direct exposure to air or heat sources; remember to close your eyes a few seconds when you read, work at a computer, or are very concentrated on an activity; humidify the environment where you work and live; hydrate; avoid using contact lenses until a healthy ocular surface is restored.

TD is a chronic pathology, and, as with all chronic conditions with no remission, the aim of the treatment is to improve the quality of life.

Therefore, it is essential to tell patients that their quality of life can improve only if they comply with the therapy provided and they leave the doctor's office knowing that the ophthalmologist has fully understood the problem and has provided a personalised therapeutic approach. The tear substitutes must be identified also as a treatment to improve a pathological state and not just a correction of the symptoms. This is why effective and efficient communication between doctor and patient is so important.

\section{Identifying the problem: the 3-step method}

Diagnosing TD is usually quite simple and does not involve significant differences compared to a routine eye examination.

A 3-step procedure can be a quick and useful method for a first-level diagnosis.

Step 1

Ask about the symptoms (a questionnaire to be administered before the examination can be useful to prevent the patient from going into detailed and not always relevant descriptions) and their distribution in terms of intensity and frequency throughout the day;

Observe the ocular surface, e.g. dirty tear surface, poor tear meniscus, hyperaemia restricted to the exposed interpalpebral area, dysmorphic disorder or eyelid inflammation, signs of meibomian gland dysfunction (foaming, swollen glands with purulent discharge or clogged glands, etc.), blinking rate and quality;

\section{Step 2}

Stain the ocular surface:

Instil 1 or $2 \%$ fluorescein to measure the break-up time (BUT) and to check for possible corneal and conjunctival damage. The addition of a yellow filter (Kodak Wratten Filter \#12) will highlight both the tear film and the conjunctival damage (if any), which is extremely important for the diagnosis; Or/and use $1 \%$ lissamine green, useful for easily highlighting conjunctival and corneal damage;

\section{Step 3}

Test ocular surface sensitivity and assess tear clearance in front of the ocular surface:

Use a cotton thread, Cochet-Bonnet aesthesiometer or a more sophisticated instrument to evaluate ocular surface sensitivity and the ability of the system to react (tear secretion is the result of a stimulation);

Re-evaluate the tear meniscus 10-15 min after staining. If the vital dye (fluorescein or lissamine green) is still present, it means that the clearance is lower than normal. This suggests a reduced tear production if the tear drainage pathway is pervious and functioning. More importantly, it indicates an increased risk of inflammation due to the surface inability to keep away toxic substances and proinflammatory cytokines.

\section{The impact of surgery: pre- and postoperative considerations}

Anterior segment surgery is one of the major causes of ocular surface alteration. In a recent multicentre study submitted to the American Society of Cataract and Refractive Surgery, over $50 \%$ of the patients who underwent cataract surgery were diagnosed with dry eye $[38,39]$. 
To prevent complications, it is essential to perform the surgery on an ocular surface as healthy as possible, identifying any possible risk factor (both regarding the patient and the surgery) and treating pre-existing conditions.

Ocular surface and TD can result in ocular discomfort and poor visual outcome with surgical results below expectations.

Ocular surface dysfunction and poor visual outcome

The corneal epithelium plays an essential role in the ocular surface system (OSS) because it maintains ocular fluid homoeostasis and contributes to the tear film through the active secretion of water.

The air-tear film interface is the most important refractive surface, and the precorneal ocular surface is responsible for $2 / 3$ of the total refractive power.

Surgery can cause tear film instability, with consequent uneven spreading across the ocular surface. This involves light deflection/scattering with the formation of a blurred image on the retina, which translates into poor visual performance.

As described in a recent publication by Baudouin et al. [40], tear film instability is one of the steps in the vicious circle of ocular surface dysfunction.

In particular, it involves tear hyperosmolarity, which is responsible for cell damage with apoptosis of conjunctival and corneal cells. It also triggers an inflammatory cascade, which further contributes to cell death, including mucin-secreting cells. These alterations worsen tear film instability and trigger a cycle of events that perpetuate the condition (Fig. 3).

Tear film alterations, with resulting epithelial suffering and inflammation, involve central and peripheral neuronal suffering. In particular, peripheral neuronal suffering reduces sensitivity, whereas central neuronal suffering is associated with deafferentation dysaesthesia [41].

The onset of symptoms and TD are consequences of this neuronal suffering.

There is also a characteristic timing in the onset of ocular discomfort symptoms, which get worse approximately one month after the surgery when postoperative anti-inflammatory eye drops are suspended [42].

All this is amplified if the patient has TD even before surgery. In such cases, the test scores return to their initial values approximately 3 months after surgery.

Therefore, it is essential to identify the patients who are at risk of developing this syndrome to prevent the onset of discomfort symptoms [43-45].

Predisposing factors of chronic inflammation

There are numerous clinical conditions and iatrogenic factors that need to be evaluated before directing a patient to anterior segment surgery.

Pre-existing clinical conditions

Predisposing conditions that may suggest the development of postoperative complications are the following: advanced age, corneal dystrophy (especially basal membrane dystrophy, which is often not diagnosed), TD, blepharitis, ocular surface inflammation even if not particularly evident, such as in the case of patients wearing contact lenses, or with pseudoexfoliation syndrome, uveitis, eyelid malpositions, use of systemic therapies that can influence tear secretion, use of topical medications that can alter the qualitative composition of the tear film, subepithelial corneal nerve plexus dysfunction and of course a pre-existing TD as well as systemic diseases, such as diabetes and rheumatologic diseases [9, 19, 46-48].

\section{Pharmacological factors}

As for preoperative medications, it is important to consider that systemic drugs can interfere with ocular surface homoeostasis, whereas topical drugs may contain chemical preservatives (detergents), which damage the permeability of the cell membrane and the cytoplasmic content, or oxidising preservatives, which pass through the cell membrane and can interfere with cell functions [49].

At low doses, oxidising preservatives are less dangerous than detergents because the eukaryotic cells produce antioxidant enzymes [50, 51].

\section{Preservatives}

Many pre- and postoperative eye drops contain surfactants, which alter the goblet cells and disrupt lipid layer stability. In particular, benzalkonium chloride leads to a glycocalyx alteration already 
Fig. 3 Vicious circle of the lacrimal dysfunction. $M G D$ meibomian gland dysfunction, $M M P$ matrix metalloproteinase, ICAMI intercellular adhesion molecule-1; GC loss, goblet cell loss

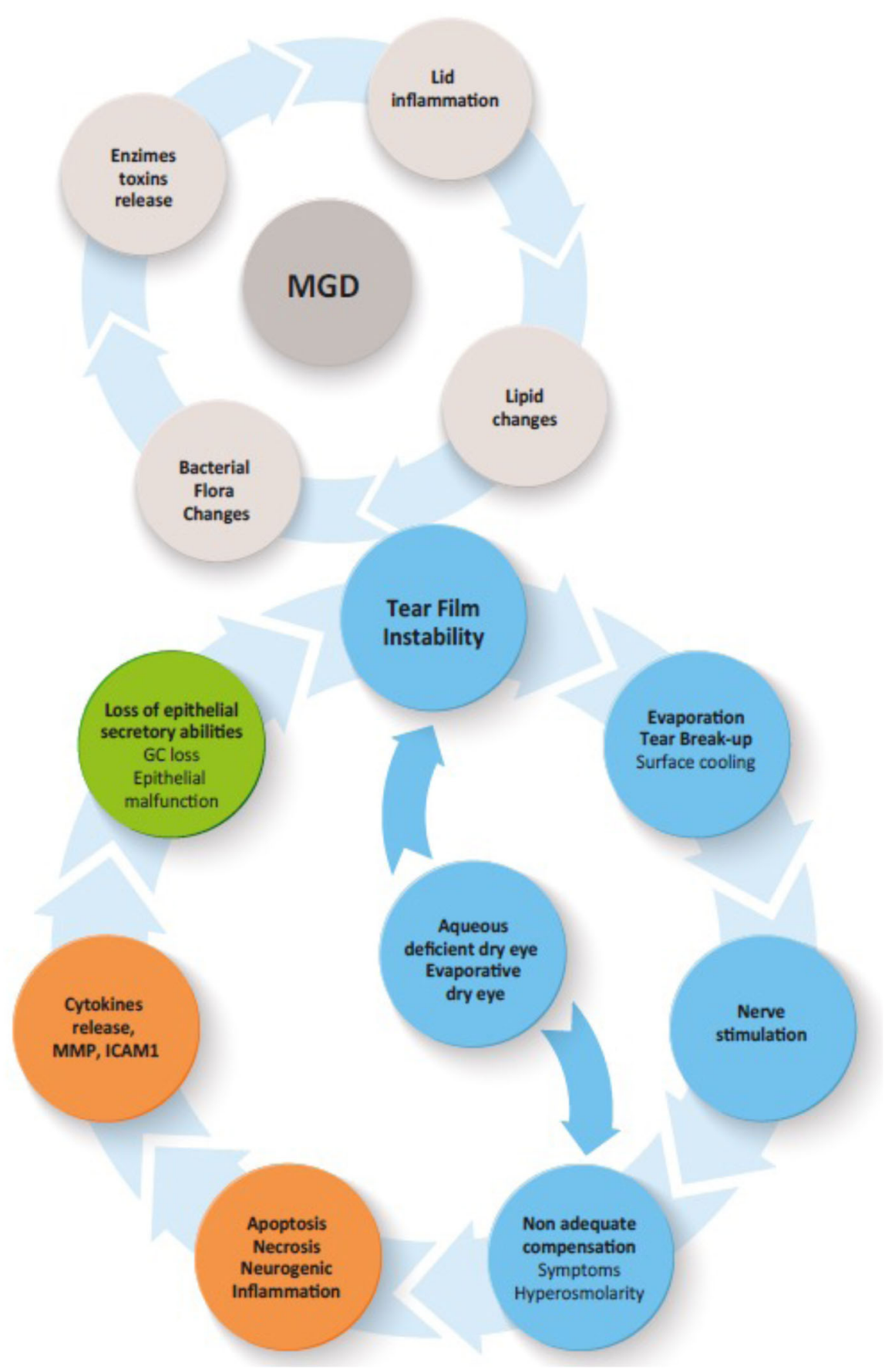

$30 \mathrm{~min}$ after its first instillation. Its action is prolonged because the average half-life of this preservative in the conjunctiva is approximately $12 \mathrm{~h} \mathrm{[52].} \mathrm{Therefore,} \mathrm{it}$ is essential to use eye drops without preservatives in the preoperative prophylaxis and improve lubrication using preservative-free tear substitutes during the postoperative period.
Surgical technique

Surgical factors (both pharmacological and those related to the surgical technique) are also important. In cataract surgery, for example, it is important to consider the epithelial toxicity of local anaesthetics and disinfectants, such as $5 \%$ povidone-iodine. 
Moreover, the application of the ocular speculum can cause trauma to eyelid muscles (weakening of the orbicularis muscle) and tissues, which can lead to incomplete blinking and loss of congruence between palpebral and bulbar conjunctiva, as well as floppy eyelid syndrome. Therefore, it is essential to use nontraumatising ocular speculum and avoid "over-tensioning" eyelid opening.

The type of incision plays a fundamental role: it has been demonstrated that the deeper the peripheral location of the incision, the higher the risk of damaging corneal innervation. The corneal innervation can take approximately 2 years to return to preoperative levels in patients undergoing extracapsular cataract extraction. A compromised corneal innervation is responsible for an abnormal healing process, increased epithelial permeability and reduced metabolic activity. Reduced corneal sensitivity involves reduced tear secretion.

As for the construction of the corneal tunnel, the site and technique are crucial to avoid an uneven surface, which could cause poor distribution of the tear film in the preceding area with epithelial suffering, reduced tear film break-up time and TD. Ultrasound and microscope light exposure can also damage the ocular surface.

Similar conditions to those observed in cataract surgery occur in the postoperative period of a corneal transplant (due to the unevenness resulting from the suture) and in retinal detachment (both ab externo and ab interno), which leads to the significant remodelling of part of the conjunctiva.

Central epithelial damage is quite frequent in transplant patients due to the poor lubrication of the corneal surface, which has lost sensitivity due to innervation damage. As a result, it undergoes blinking-induced erosions, especially in the event that slightly tight sutures have flattened the surface.

The association of reduced lubrication with an inflammatory state demonstrates the importance of lubrication. In fact, TD in the form of excessive tear evaporation is the most frequently undiagnosed and underestimated cause of ocular surface inflammation. In the event of a corneal transplant, the inflammatory state of the ocular surface will result in the activation of antigen-presenting cells on the ocular surface with transplant rejection [53, 54].

In patients undergoing glaucoma filtration surgery, it is important to prevent the closure of the bleb.
Moreover, dry eye can be observed in these patients, and lissamine green staining highlights areas of epithelial damage above the bleb. TD is associated with inflammation and, as a result, fibroblast recruitment. Therefore, it is essential to lubricate the ocular surface to reduce inflammation so preventing fibrosis and the formation of adherence between the conjunctiva and the sclera.

As for photorefractive surgery, both PRK and LASIK determine a significant damage of corneal nerves so inducing altered sensitivity and innervational problems. These trigger compensatory mechanisms that lead to the onset of important symptoms. Postoperative discomfort symptoms can be compared to nerve deafferentation, similar to the condition that occurs in neuropathological or neurosurgical lesions. Residual nerve fibres mediate dysaesthesia, resulting from partial peripheral lesions with loss of small afferent fibres. Pathological pain can be a problem in these patients, because the surgery causes the release of $\mathrm{PGE}_{2}$ and $\mathrm{PGI}_{2}$, which determines a sensitisation characterised by a reduced activation threshold, increased response to certain stimuli, and onset of spontaneous nociceptor activity. This sensitisation can manifest itself as hyperalgesia (i.e. an enhanced nociceptive response to certain noxious stimuli) or allodynia (i.e. sensitisation to pain in response to previously non-noxious stimuli). In these cases, the clinical picture, characterised by the typical ocular surface changes, does not justify the symptoms reported [41].

\section{Peri- and postoperative therapies}

Today, it is known that the corneoconjunctival epithelium is not an inert tissue. In fact, it synthesises proinflammatory cytokines (interleukins and metalloproteases), or molecules that attract immunocompetent cells from the peripheral blood, thereby creating a lymphocyte homing process, which maintains the inflammatory state on the ocular surface.

Being a multifactorial condition, the preventive/ therapeutic approach should be dynamic and try to identify the dominating mechanism at each follow-up to define a suitable treatment that aims at correcting the inefficient mechanism $[43,55]$.

In particular, the following can be very useful: eyelid hygiene in patients with meibomian gland dysfunction, avoiding the use of eye drops with 
vasoconstrictors, adopting (if possible before the surgery) a therapy with a tear substitute that acts on tear instability, epithelial damage and inflammation (vicious circle) and continuing it during the postoperative period $[38,44]$.

\section{Therapeutic approach: the $3+2$ method}

Ocular surface therapies should aim to correct the alterations of all the structures that are part of the lacrimal functional unit. A malfunction of these structures can lead to TD. Ocular surface structures are continuously exposed to the action of the external environment and therefore require efficient tear production, distribution and turnover $[3,9,56]$.

Tear film, lacrimal glands (main and accessory glands, meibomian glands, goblet cells and all ocular surface secreting cells), tear drainage pathway, and corneal and conjunctival epithelium activity make up the functional unit, which protects the ocular surface by producing and maintaining an efficient tear film. The activity of the functional unit structures is regulated by the nervous system (whose endings are particularly numerous on the ocular surface) and hormones that reach it through the bloodstream.

Any agent that can alter even one of the functional unit structures can disrupt the stability of the tear film and lead to ocular surface diseases, thereby outlining the clinical picture of dry eye. This is not just the result of a tear deficiency, but a complex pathological picture, in which the tear film is unbalanced and does not provide the ocular surface with enough nourishment and protection. This alteration results in an imbalance in the production of electrolytes, proteins, and mucins, with a permanent damage to the corneal and conjunctival epithelial cells, and the activation of nerve fibres, which try to trigger the secretory activity as a compensatory mechanism. If the compensatory mechanisms activated by the functional unit structures fail to recreate a balanced system, they will trigger a series of epithelial alterations. Exposed to the noxious stimulus of a dysfunctional tear film, the epithelium will undergo the secretion of proapoptotic and proinflammatory substances, which induce a vicious circle and trigger a state of chronic suffering of the ocular surface structures. The maintenance of this vicious circle is based on three main pathogenetic factors: (1) tear film instability, (2) epithelial disease and (3) ocular surface inflammation associated or not to an innervation alteration and meibomian glands dysfunction (which contributes to tear film instability and activation of inflammation).

A therapeutic approach aiming at interrupting the vicious circle at the base of the ocular surface suffering must aim to correct the alterations of each of these aspects: this will promote the restoration of a normal homoeostasis. An appropriated therapy should be simultaneously addressed towards all these factors. The choice should be taken according to the $3+2$ method (Table 5).

\section{Address tear film instability}

Tear volume, which tends to decrease with the increased evaporation, plays a primary role in tear film stabilisation. In this context, mucomimetic substances play an essential role. Among these substances, sodium hyaluronate (HA) is nowadays considered the gold standard.

HA is a mucopolysaccharide with a molecular weight ranging between $2 \times 10^{5}$ and $10 \times 10^{6} \mathrm{D}$. It is composed of repeating disaccharide units forming a highly negatively charged polymer, which can bind large amounts of water. This polymer has rheological properties characterised by non-Newtonian behaviour, i.e. it is provided with high viscosity, which quickly decreases when forces that determine a quick displacement are applied. This is what happens when eyelids close during a blink. This rheological property is very similar to that of normal tears. HA is present on a normal ocular surface, having been found in tears, glycocalyx, at the interface between cells and the basal membrane of the conjunctival epithelium, corneal epithelium, stroma, keratocytes, and in lacrimal gland acinar cells $[57,58]$. Moreover, it has been proven that the $\mathrm{CD} 44$ receptor for $\mathrm{HA}$ is found in the cornea always closely associated with HA, thereby demonstrating the role played by this combination of molecules in modulating adhesion, growth and migration of corneal epithelial cells [57].

It has been demonstrated that the use of HA in dry eye therapies can improve the ocular surface significantly by increasing tear film stability, improving the condition of the corneoconjunctival epithelium, reducing squamous metaplasia and promoting the reappearance of muciparous goblet cells in the conjunctival epithelium $[59,60]$. The HA formulation can vary and 
Table 5 The $3+2$ method

\begin{tabular}{lll}
\hline Tear film instability & Inflammation & Epithelial damage \\
\hline Hyaluronic Acid 0.15-0.2\% & Fluid tear substitute & Trehalose \\
PVA 0.1\% & Corticosteroids (cortisol, prednisone, etc.) & CMC 1\% \\
HP-Guar & Cyclosporine A & Xanthan Gum \\
Carbopol & Omega 3 & Hyaluronic Acid 0.4-0.5\% \\
Dextran & Proinflammatory molecules inhibitors & Carbopol \\
etc. & etc. & etc. \\
\hline
\end{tabular}

A recommended therapeutic approach for the management of tear dysfunction

MGD treatment: eyelid hygiene + hot compresses + antibiotics (topic or systemic if necessary)

Innervation treatment: vitamins? Growth factors? Neurotrophic factors?

$P V A$ polyvinyl alcohol, Hp-guar hydroxypropyl guar, CMC carboxymethylcellulose

depends on the molecular weight and concentration used. The molecular weight can also depend on the origin of the molecule, i.e. from rooster comb extraction, bacterial fermentation, or chemical synthesis. The last one can reach an extremely high molecular weight, thanks to the cross-linking technique, which results in a group of molecules called hyalans [57]. The formulation of HA eye drops chosen must be based on the conditions of the ocular surface, in order to restore the normal tear film as far as possible and obtain the best possible microenvironment for the efficient repair of damaged structures [60].

Quit ocular surface inflammation

An anti-inflammatory treatment is the second pillar of dry eye therapy. The exact pathogenesis of inflammation has not been firmly established: it could be due to the surface's inability to keep toxic substances and proinflammatory cytokines away; a fluid tear substitute (not gel) with hydrophilic, mucomimetic and lubricating properties in early states of the disease is often enough to wash the ocular surface.

On the other hand, if the inflammation is clinically evident, it is probably due to an initiating stimulus that can alter ocular surface homoeostasis: environmental stress (UV-ROS, chemicals), alterations in the tear film compositions secondary to lacrimal gland inflammation, pathologic changes of neural traffic, hyperosmolarity, microtrauma from eyelids during blinking are the most recognised. These factors could play a role in inducing loss of ocular surface immunohomoeostasis and triggering Dry Eye Disease. This must be worked out in the case of evident epithelial suffering and must begin with a corticosteroid treatment to allow the regression, as quickly as possible, of the production of proinflammatory substances. The molecules used must have medium power and, preferably, a composition that reduces their penetration into the anterior chamber, in order to reduce, as much as possible, intraocular side effects such as increased intraocular pressure and onset of cataract. With this aim, molecules with lipophilic or fluorinated residues are to be preferred [61].

Today, corticosteroids can be associated with cyclosporine, a drug that has been recently introduced in the European market. Its immunosuppressive effect combats the activity and recruitment of T lymphocytes and inhibits apoptosis. It is important to consider that the clinical effectiveness of cyclosporine begins to manifest 2-3 months after administration. Therefore, it is important to start the anti-inflammatory treatment administering corticosteroids and cyclosporine together to obtain a rapid response to the treatment and maintain long-term results with cyclosporine alone, which is less exposed to the onset of side effects [62].

Also omega-3 fatty acids can help reduce the production of proinflammatory substances. In fact, they protect tissues from the inflammatory insult, thanks to the competitive inhibition of prostaglandin $\mathrm{E}_{2}$ production, and the production of metabolites known as resolvins, which block the inflammation by inhibiting immunocompetent cells [63]. 
Epithelial protection

The third pillar of dry eye therapy is the epithelium protection. Nowadays, the conditions of the epithelial cells can be improved not only by intervening on the quality of the tear film but also by supplying substances that can protect the cells from degenerative processes, which trigger the production of proinflammatory and proapoptotic cytokines [40]. It has been demonstrated that some molecules are particularly effective in protecting the epithelium. Among these, trehalose has drawn particular interest in ophthalmology, as several studies have shown that it helps improve the treatment of ocular surface disorders.

This molecule is synthesised by several types of cells as a response to stress represented by extreme cold, hot, oxidation and dehydrating conditions. In particular, trehalose is synthesised by bodies as a reaction to water-deficit stress. In fact, it promotes anhydrobiosis, i.e. the ability to resist water deficit and drought. This molecule is characterised by high stability. Its behaviour when exposed to heat is particularly interesting. It first melts at $97{ }^{\circ} \mathrm{C}$; then, with a further increase in temperature, it chrysalises. It resolidifies at $130{ }^{\circ} \mathrm{C}$ and then melts again at $203{ }^{\circ} \mathrm{C}$.

Trehalose preserves the integrity of the cells and their intracellular organelles through multiple mechanisms, which are not yet fully known [64].

In this regard, there are three theories:

1. The vitrification theory, according to which the trehalose inside the cells creates hydrogen bonds with protein structures, thereby forming a thin hydrocolloid matrix, which protects the cells from extracellular and intracellular environmental imbalance;

2. The preferential exclusion theory, according to which trehalose interacts with water molecules, determining a redistribution with an increase in compactness and, as a result, in protein stability;

3. The water replacement theory, with the formation of hydrogen bonds that maintain the threedimensional structure, thereby stabilising the biomolecules, which, in this way, do not undergo denaturation.

The bioprotective effect of trehalose in ocular surface alterations results from the preservation of the integrity of proteins and lipids, protection against oxidative and osmotic stress, and against hypoxia and anoxia and, consequently, from apoptosis-induced cell death.

As for the preservation of the integrity of proteins and lipids, trehalose maintains their configuration by binding with proteins. This explains the protective effect against denaturation under stress conditions, such as dehydration and frostbite.

Protection against denaturation is particularly important for the preservation of intracellular enzyme system functions, cell membrane functional properties (e.g. transport of calcium) and cellular content.

The protective effect against osmotic stress is also important for cytoprotection, as the main ocular surface alteration mechanism is frequently represented by the osmotic imbalance with the extracellular environment. Trehalose has also an antioxidant effect and its use has proven to prevent damage caused by oxygen free radicals combined with heat shock. Moreover, it increases the tolerance to anoxia because by reducing protein aggregation and maintaining their conformation, it promotes recovery after exposure to anoxic conditions.

The results of preclinical studies have shown that trehalose:

1. Hydrates and protects corneal cells from death by desiccation [64]

2. Improves resistance of ocular surface epithelium through suppression of apoptosis [65]

3. Protects the cornea from UVB-induced damage [66]

4. Prevents fibrosis and post-trabeculectomy adhesions [67].

Clinical studies based on this evidence have evaluated the efficacy of trehalose in patients with mild to severe TD compared to saline solution [68] or other tear substitutes, such as hyaluronic acid and hydroxymethylcellulose [69].

The results of these studies have shown that trehalose:

1. Improves ocular surface discomfort in patients with mild to severe TD [68]

2. Demonstrates greater efficacy in terms of improvement in subjective symptoms and objective parameters compared to tear substitutes, usually used in patients with mild to severe TD [69]. 
Finally, another study evaluating the corneal epithelium exposed to the toxic action of alcohol has shown that trehalose can protect epithelial cells, preserving cell membrane structures and internal organelles. This suggests that a pretreatment with trehalose can help patients who undergo photorefractive keratectomy (PRK) improving epithelial healing after surgery [70].

Meibomian glands dysfunction and innervation alteration are other two therapeutic targets to take care of.

Meibomian gland dysfunction is responsible for the creation of a lipid layer in the poorly efficient tear film, thereby exposing it to increased evaporation, which results in TD [71]. Modifications in the ocular surface microenvironment determine a modification in the bacterial flora, which activates innate immunity through toll-like receptors, with resulting inflammation [72]. Meibomian gland secretion is altered; therefore, it does not liquefy at the temperature of the ocular surface and remains in the excretory ducts of the glands, triggering a chronic inflammatory stimulus. The therapy is based on the use of high temperature $\left(40-45^{\circ} \mathrm{C}\right)$ through warm, wet compresses or eyelid-warming devices, such as Blephasteam, which allow altered lipids to melt by raising the temperature [73]. In addition to eyelid warming, the use of topical and systemic antibiotics can also help. These antibiotics have two mechanisms of action. On the one hand, they promote bacterial flora regularisation, decrease the secretion of bacterial lipases that act on altered lipid secretions and release fatty acids that are irritating to the glandular ducts. On the other hand, they have a direct anti-inflammatory effect, blocking the release of proinflammatory substances, such as metalloproteinases. The classes of antibiotics used to this end are tetracyclines (rolitetracycline, minocycline and doxycycline), administered both topically and systemically, topical macrolides (azithromycin) and topical fluoroquinolones (ofloxacin) [2, 74, 75].

The ocular surface, and especially the cornea, is the most highly innervated structure in the human body. The innervation plays a primary role in the homoeostasis of the functional unit, conditioning the signs and symptoms resulting from its dysfunction. In fact, a reduction in sensitivity involves hypolacrimation, resulting in the reduced production of epithelium trophic factors, such as epidermal growth factor
(EGF), which is essential for epithelial trophism. In extreme cases, this epithelial suffering can lead to the formation of neurotrophic ulcers, which could seriously compromise visual function. When sensitivity is highly compromised, the clinical picture can be accompanied by mild discomfort. However, there are cases in which chronic inflammation leads to the stimulation of the nociceptors on the ocular surface, resulting in severe discomfort, which may not correspond with the clinical signs. In such cases, neuropathy can be both peripheral and central. A therapy for ocular surface innervation alterations is yet to be defined, although there are a few measures that can be taken. Again, omega-3 fatty acids can help, because one of their metabolites, neuroprotectin $\mathrm{D}$, has neuroprotective properties [76, 77]. Nerve growth factor (NGF) can be useful in the event of reduced sensitivity. In fact, it has been proven to restore sensitivity and promote the healing of neurotrophic ulcers in association (if necessary) with a therapy with glycosaminoglycan (GAG) analogues, which has been recently made available in the market [78].

Therapies for ocular surface disorders must be complete, i.e. they must deal simultaneously with the alterations of the structures involved in the pathological process and be dynamic. Therefore, it is important to avoid fixed treatment regimens and adopt therapies that can change any time if the patient's conditions require so [79]. This therapeutic approach (with progressive adjustments to the patient's conditions) allows for the improvement and stabilisation of the patient's clinical conditions and an overall improvement in their quality of life.

The treatment for ocular disorder should take into consideration the use of formulations without preservatives [the most commonly used preservative is the benzalkonium chloride (BAK)] [80].

Patients with dry eye are at particular risk; in fact, the low tear volume allows higher concentrations of BAK to remain in contact with the cornea for longer periods of time [81].

Long-term use of preservative-containing artificial tears is associated with an increased risk of adverse events and epithelial surface damage and diminished compliance due to ocular irritation [50].

Experimental studies in cultured conjunctival cells have shown increased cytotoxic effects of BAK in hyperosmolarity conditions with characteristic cell death process, including caspase-dependent and 
Fig. 4 Multi-item flowchart to better define the diagnosis and assess the better treatment in patients with tear dysfunction

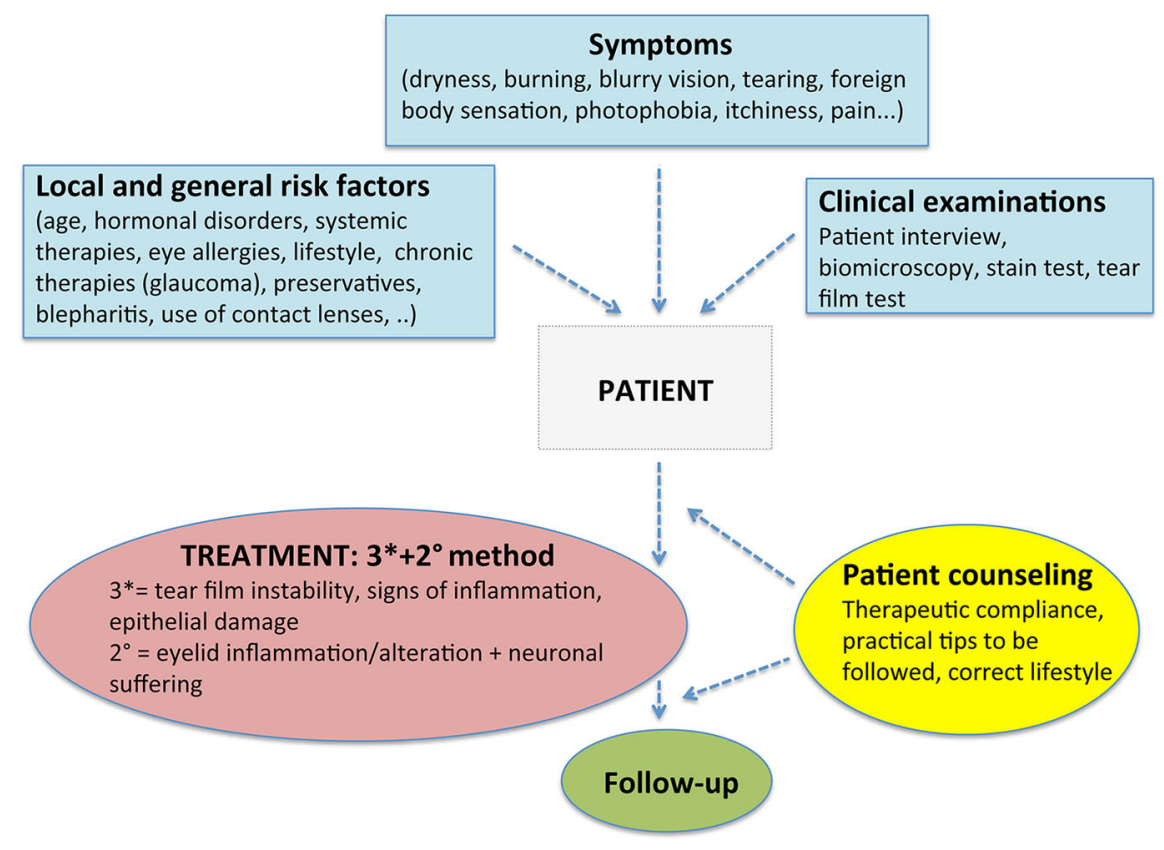

(dryness, burning, blurry vision, tearing, foreign body sensation, photophobia, itchiness, pain...) caspase-independent apoptosis and oxidative stress [51]. This suggests that BAK administered in an eye already submitted to hyperosmolar conditions would be more toxic than in a healthy normal ocular surface.

That is why preservative-free formulation is absolutely necessary as well as therapies for ocular surface disorders and for patients with lacrimal dysfunction.

\section{Conclusions}

TD is highly prevalent in the population aged over 45 years and consists of the imbalance of the ocular surface functional unit. Its pathogenesis is multifactorial, and the clinical picture varies greatly, ranging from very mild to virtually invalidating conditions with a severe impact on the quality of life. In the last few years, an increasing interest arouse, due to the difficulties in diagnosis and treatment. The most recent researches have shown that the ocular surface epithelium is the main target of the disease as a consequence of an altered and non-functional tear film. The epithelium will promote inflammation and apoptosis, through the production of proinflammatory and proapoptotic molecules as the consequence of the insult. A nervous impairment and the establishment of a vicious cycle, determining the chronicity of the process, will follow.

The need for a clear identification of the different involvement of each component of the ocular surface structure, in order to assess the best treatment possible, has prompted us to identify a useful approach to diagnose and treat TD (Fig. 4). The main aspect to be considered is that, being dry eye a multifactorial disease with a multiform presentation and course, the treatment should be adapted to the patient's condition rather than be just a standard treatment. Using the simple flowchart illustrated in Fig. 4 will guide from the right diagnosis to the best treatment possible.

Acknowledgements This paper was supported by an unrestricted grant from Théa Farma S.p.A.

\section{Compliance with ethical standards}

Conflict of interest The authors report no conflicts of interest in this work.

Open Access This article is distributed under the terms of the Creative Commons Attribution 4.0 International License (http:// creativecommons.org/licenses/by/4.0/), which permits unrestricted use, distribution, and reproduction in any medium, provided you give appropriate credit to the original author(s) and the source, provide a link to the Creative Commons license, and indicate if changes were made.

\section{References}

1. Rolando M (2014) Sostituti lacrimali ad azione multipla di nuova generazione: il trattamento ad ampio spettro delle disfunzioni lacrimali. Of Focus 19:1-12 
2. Research in dry eye: report of the Research Subcommitte of the International Dry Eye WorkShop (2007). Ocul Surf 5(2):179-193

3. Rolando M, Zierhut M (2001) The ocular surface and tear film and their dysfunction in dry eye disease. Surv Ophthalmol 45:S203-S210

4. Bron AJ, Yokoi N, Gafney E, Tiffany JM (2009) Predicted phenotypes of dry eye: proposed consequences of its natural history. Ocul Surf 7:78-92

5. Rolando M, Refojo MF, Kenyon KR (1983) Increased tear evaporation in eyes with keratoconjunctivitis sicca. Arch Ophthalmol 101:557-558

6. Gilbard JP, Farris RL, Santamaria J (1978) Osmolarity of tear microvolumes in keratoconjunctivitis sicca. Arch Ophthalmol 96:677-681

7. Parra A, Gonzalez-Gonzalez O, Gallar J, Belmonte C (2014) Tear fluid hyperosmolality increases nerve impulse activity of cold thermoreceptor endings of the cornea. Pain 155:1481-1491

8. Rolando M, Terragna F, Giordano G, Calabria G (1990) Conjunctival surface damage distribution in keratoconjunctivitis sicca. An impression cytology study. Ophthalmologica 200:170-176

9. Stern ME, Beuerman RW, Fox RI, Gao J, Mircheff AK, Pflugfelder SC (1998) The pathology of dry eye: the interaction between the ocular surface and lacrimal glands. Cornea 17:584-589

10. Barabino S, Shen L, Chen L, Rashid S, Rolando M, Dana R (2005) The controlled-environment chamber: a new mouse model of dry eye. Investig Ophthalmol Vis Sci 46: 2766-2771

11. Ciprandi G, Buscaglia S, Pesce G, Lotti R, Rolando M, Bagnasco M, Canonica GW (1994) Effects of conjunctival hyperosmolar challenge in allergic subjects and normal controls. Int Arch Allergy Immunol 104:92-96

12. Luo L, Li DQ, Doshi A, Farley W, Corrales RM, Pflugfelder SC (2004) Experimental dry eye stimulates production of inflammatory cytokines and MMP-9 and activates MAPK signaling pathways on the ocular surface. Investig Ophthalmol Vis Sci 45(12):4293-4301

13. Rolando M, Barabino S, Mingari C et al (2005) Distribution of conjunctival HLA-DR expression and the pathogenesis of damage in early dry eyes. Cornea 24:951-954

14. Sullivan BD, Crews LA, Messmer EM et al (2014) Correlations between commonly used objective signs and symptoms for the diagnosis of dry eye disease: clinical implications. Acta Ophthalmol 92:161-166. doi:10.1111/aos.12012

15. Sullivan BD, Crews LA, Sonmez B et al (2012) Clinical utility of objective tests for dry eye disease: variability over time and implications for clinical trials and disease management. Cornea 31:1000-1008

16. Schaumberg DA, Buring JE, Sullivan DA, Dana MR (2001) Hormone replacement therapy and dry eye disease. JAMA 286:2114-2119

17. Muntz A, Subbaraman LN, Sorbara L, Jones L (2015) Tear exchange and contact lenses: a review. J Optom 8:2-11

18. PDR Staff (2010) Physicians' desk reference, PDR Network, 64th edn. LLC, Montvale

19. Moss SE, Klein R, Klein BE (2000) Prevalence of and risk factors for dry eye disease. Arch Ophthalmol 118:1264-1268
20. Sreebny LM, Schwartz SS (1997) A reference guide to drugs and dry mouth-2nd edition. Gerodontology 14:33-47

21. Schein OD, Hochberg MC, Muñoz B et al (1999) Dry eye and dry mouth in the elderly: a population-based assessment. Arch Intern Med 159:1359-1363

22. Fraunfelder FT, Fraunfelder FW, Chambers WA (2008) Clinical ocular toxicology. Elsevier Saunders, Philadelphia

23. Guggenheimer J, Moore PA (2003) Xerostomia: etiology, recognition and treatment. J Am Dent Assoc 134:61-69

24. Maino DM, Tran S, Mehta F (2000) Side effects of chemotherapeutic oculo-toxic agents: a review. Clin Eye Vis Care 12:113-117

25. Wong J, Lan W, Ong LM, Tong L (2011) Non-hormonal systemic medications and dry eye. Ocul Surf 9:212-226

26. Aragona P, Puzzolo D, Micali A, Ferreri G, Britti D (1998) Morphological and morphometric analysis on the rabbit conjunctival goblet cells in different hormonal conditions. Exp Eye Res 66:81-88

27. Aragona P, Cannavò SP, Borgia F, Guarneri F (2005) Utility of studying the ocular surface in patients with acne vulgaris treated with oral isotretinoin: a randomized controlled trial. Br J Ophthalmol 152:576-578

28. Fraunfelder FT, LaBraico JM, Mayer SM (1985) Adverse ocular reactions possibly associated with isotretinoin. Am J Ophthalmol 100:534-537

29. Slabaugh SL, Maio V, Templin M, Abouzaid S (2010) Prevalence and risk of polypharmacy among the elderly in an outpatient setting: a retrospective cohort study in the Emilia-Romagna region, Italy. Drugs Aging 27:1019-1028

30. Gu Q, Dillon CF, Burt VL (2010) Prescription drug use continues to increase: US prescription drug data for 2007-2008. NCHS Data Brief 42:1-8

31. Fraunfelder FT, Gilbaugh JH (2008) Retire right: 8 scientifically proven traits you need for a happy, fulfilling retirement. Penguin, New York

32. Fraunfelder FT, Sciubba JJ, Mathers WD (2012) The role of medications in causing dry eye. J Ophthalmol 2012:285851. doi:10.1155/2012/285851

33. Baudouin C, Aragona P, Van Setten G, ODISSEY European Consensus Group members et al (2014) Diagnosing the severity of dry eye: a clear and practical algorithm. Br J Ophthalmol 98:1168-1176

34. Rosenthal P, Borsook D (2012) The corneal pain system. Part I: the missing piece of the dry eye puzzle. Ocul Surf 10:2-14

35. Behrens A, Doyle JJ, Stern L et al (2006) Dysfunctional tear syndrome: a Delphi approach to treatment recommendations. Cornea 25:900-907

36. Wan KH, Chen LJ, Young AL (2016) Depression and anxiety in dry eye disease: a systematic review and metaanalysis. Eye. doi:10.1038/eye.2016.186

37. Na KS, Han K, Park YG, Na C, Joo CK (2015) Depression, stress, quality of life, and dry eye disease in Korean women: a population-based study. Cornea 34:733-738. doi:10.1097/ ICO.0000000000000464

38. Sutu C, Fukuoka H, Afshari NA (2016) Mechanisms and management of dry eye in cataract surgery patients. Curr Opin Ophthalmol 27:24-30. doi:10.1097/ICU.000000000 0000227

39. Kasetsuwan N, Satitpitakul V, Changul T, Jariyakosol S (2013) Incidence and pattern of dry eye after cataract 
surgery. PLoS ONE 8(11):e78657. doi:10.1371/journal. pone. 0078657

40. Baudouin C, Aragona P, Messmer EM, Tomlinson A, Calonge M, Boboridis KG, Akova YA, Geerling G, Labetoulle M, Rolando M (2013) Role of hyperosmolarity in the pathogenesis and management of dry eye disease: proceedings of the OCEAN group meeting. Ocul Surf 11:246-258

41. Rosenthal P, Borsook D (2016) Ocular neuropathic pain. Br J Ophthalmol 100:128-134. doi:10.1136/bjophthalmol2014-306280

42. Mencucci R, Boccalini C, Caputo R, Favuzza E (2015) Effect of a hyaluronic acid and carboxymethylcellulose ophthalmic solution on ocular comfort and tear film instability after cataract surgery. J Cataract Refract Surg 41:1699-1704. doi:10.1016/j.jcrs.2014.12.056

43. Cho YK, Kim MS (2009) Dry eye after cataract surgery and associated intraoperative risk factors. Korean J Ophthalmol 23:65-73. doi:10.3341/kjo.2009.23.2.65

44. Li XM, Hu L, Hu J, Wang W (2007) Investigation of dry eye disease and analysis of the pathogenic factors in patients after cataract surgery. Cornea 26:S16-S20

45. Sun XG, Shi YY, Zhang C (2008) Not to ignore the dry eye of cataract patients after surgery. Zhonghua Yan Ke Za Zhi 44:291-292

46. Manaviat MR, Rashidi M, Afkhami-Ardekani M (2008) Prevalence of dry eye disease and diabetic retinopathy in type 2 diabetic patients. Eur J Ophthalmol 18:572-577

47. Gomes PJ, Welch D, Abelson MB (2005) Methodologies for the study of ocular surface disease. Ocul Surf 3:143-154

48. Wolfe F, Michaud K (2008) Prevalence, risk, and risk factors for oral and ocular dryness with particular emphasis on rheumatoid arthritis. J Rheumatol 35:1023-1030

49. Walker TD (2004) Benzalkonium toxicity. Clin Exp Ophthalmol 32:657

50. Baudouin C, Labbé A, Liang H, Pauly A, Brignole-Baudouin F (2010) Preservatives in eye drops: the good, the bad and the ugly. Prog Retin Eye Res 29:312-334

51. Clouzeau C, Godefroy D, Riancho L, Rostène W, Baudouin C, Brignole-Baudouin F (2012) Hyperosmolarity potentiates toxic effects of benzalkonium chloride on conjunctival epithelial cells in vitro. Mol Vis 18:851-863

52. Chung So-Hyang et al (2006) Impact of short-term exposure of commercial eyedrops preserved with benzalkonium chloride on precorneal mucin. Mol Vis 12:415-421

53. Cetinkaya S, Mestan E, Acir NO, Cetinkaya YF, Dadaci Z, Yener HI (2015) The course of dry eye after phacoemulsification surgery. BMC Ophthalmol 15:68

54. Ram J, Gupta A, Brar G, Kaushik S, Gupta A (2002) Outcomes of phacoemulsification in patients with dry eye. J Cataract Refract Surg 28:1386-1389

55. De Paiva CS, Chen Z, Koch DD, Hamill MB, Manuel FK, Hassan SS, Wilhelmus KR, Pflugfelder SC (2006) The incidence and risk factors for developing dry eye after myopic LASIK. Am J Ophthalmol 141:438-445

56. Rolando M, Geerling G, Dua HS, Benítez-del-Castillo JM, Creuzot-Garcher C (2010) Emerging treatment paradigms of ocular surface disease: proceedings of the ocular surface workshop. Br J Ophthalmol 94:1-9

57. Aragona P (2004) Hyaluronan in the treatment of ocular surface disorders. In: Garg HG, Hales CA (eds) Chemistry and biology of hyaluronan. Elsevier Ltd, New York, pp 529-551

58. Oya T, Obata H, Miyata K, Tsuro T, Miyauchi S (1995) Quantitative analyses of glycosaminoglycans in tear fluids in normal eyes and eye with corneal epithelial disorders. Nippon Ganka Gakkai Zasshi 99:302-307

59. Aragona P, Papa V, Micali A, SantoconoM Milazzo G (2002) Long term treatment with sodium hyaluronate-containing artificial tears reduces ocular surface damage in patients with dry eye. Br J Ophthalmol 86:181-184

60. Aragona P, Di Stefano G, Ferreri F, Spinella R, Stilo A (2002) Sodium hyaluronate eye drops of different osmolarity for the treatment of dry eye in Sjogren's syndrome patients. Br J Ophthalmol 86:879-884

61. Aragona P, Spinella R, Rania L, Postorino E, Sommario MS, Roszkowska AM, Puzzolo D (2013) Safety and efficacy of $0.1 \%$ clobetasone butyrate eye drops in the treatment of dry eye in Sjögren syndrome. Eur J Ophthalmol 23:368-376

62. Aragona $\mathrm{P}$ (2014) Topical cyclosporine: are all indications justified? Br J Ophthalmol 98:1001-1002

63. Dartt DA, Hodges RR, Li D, Shatos MA, Lashkari K, Serhan CN (2011) Conjunctival goblet cell secretion stimulated by leukotrienes is reduced by resolvins D1 and E1 to promote resolution of inflammation. J Immunol 186:4455-4466

64. Matsuo T (2001) Trehalose protects corneal epithelial cells from death by drying. Br J Ophthalmol 85:610-612

65. Chen W, Zhang X, Liu M, Zhang J, Ye Y, Lin Y, Luyckx J, Qu J (2009) Trehalose protects against ocular surface disorders in experimental murine dry eye through suppression of apoptosis. Exp Eye Res 89:311-318

66. Cejkova J, Ceika C, Ardan T, Sirc J, Michalek J, Luyckx J (2010) Reduced UVB-induced corneal damage caused by reactive oxygen and nitrogen species and decreased changes in corneal optics after trehalose treatment. Histol Histopathol 25:1403-1416

67. Takeuchi K, Nakazawa M, Ebina Y, Sato K, Metoki T, Miyagawa Y, Ito T (2010) Inhibitory effects of trehalose on fibroblast proliferation and implications for ocular surgery. Exp Eye Res 91:567-577

68. Matsuo T, Tsuchida Y, Morimoto N (2002) Trehalose eye drops in the treatment of dry eye disease. Ophthalmology 109:2024-2029

69. Matsuo T (2004) Trehalose versus hyaluronan or cellulose in eye drops for the treatment of dry eye. Jpn J Ophthalmol 48:321-327

70. Aragona P, Colosi P, Rania L, Colosi F, Pisani A, Puzzolo D, Micali A (2014) Protective effects of trehalose on the corneal epithelial cells. Sci World J 2014:717-835

71. Baudouin C, Messmer EM, Aragona P, Geerling G, Akova YA, Benítez-Del-Castillo J, Boboridis KG, Merayo-Lloves J, Rolando M, Labetoulle M (2016) Revisiting the vicious circle of dry eye disease: a focus on the pathophysiology of meibomian gland dysfunction. $\mathrm{Br} \quad \mathrm{J}$ Ophthalmol 100:300-306

72. Musumeci M, Aragona P, Bellin M, Maugeri F, Rania L, Bucolo C, Musumeci S (2009) Acidic mammalian chitinase in dry eye conditions. Cornea 28:667-672

73. Wang MT, Gokul A, Craig JP (2015) Temperature profiles of patient-applied eyelid warming therapies. Contact Lens Anterior Eye 38:430-434 
74. Zhang L, Su Z, Zhang Z, Lin J, Li DQ, Pflugfelder SC (2015) Effects of azithromycin on gene expression profiles of proinflammatory and anti-inflammatory mediators in the eyelid margin and conjunctiva of patients with meibomian gland disease. JAMA Ophthalmol 133:1117-1123

75. Thode AR, Latkany RA (2015) Current and emerging therapeutic strategies for the treatment of meibomian gland dysfunction (MGD). Drugs 75:1177-1185

76. He J, Bazan HE (2010) Omega-3 fatty acids in dry eye and corneal nerve regeneration after refractive surgery. Prostaglandins Leukot Essent Fatty Acids 82:319-325

77. He J, Cortina MS, Kakazu A, Bazan HE (2015) The PEDF neuroprotective domain plus DHA induces corneal nerve regeneration after experimental surgery. Investig Ophthalmol Vis Sci 56:3505-3513
78. Cochener B, Muraine M (2012) A new matrix therapy agent in the treatment of corneal ulcers resistant to conventional treatments. Acta Ophthalmol. doi:10.1111/j.1755-3768. 2012.2522.x

79. Aragona P, Rolando M (2013) Towards a dynamic customised therapy for ocular surface dysfunctions. $\mathrm{Br} \mathrm{J}$ Ophthalmol 97:955-960

80. Wilson WS, Duncan AJ, Jay JL (1975) Effect of benzalkonium chloride on the stability of the precorneal tear film in rabbit and man. Br J Ophthalmol 59:667-669

81. Asbell PA (2006) Increasing importance of dry eye disease and the ideal artificial tear: consensus views from a roundtable discussion. Curr Med Res Opin 22:2149-2157 